\title{
XIV. On the spectra given by carbon and some of its compounds; and, in particular, the "Swan" spectrum
}

\section{W. Marshall Watts D.Sc.}

To cite this article: W. Marshall Watts D.Sc. (1914) XIV. On the spectra given by carbon and some of its compounds; and, in particular, the "Swan" spectrum, Philosophical Magazine Series 6, 28:163, 117-128

To link to this article: http://dx.doi.org/10.1080/14786440708635189

曲 Published online: 08 Apr 2009.

Submit your article to this journal $[\pi$

Џll Article views: 2

Q View related articles $\longleftarrow$

Citing articles: 2 View citing articles $\square$ 


\section{[ 117 ]}

XIV. On the Spectra given by Carbon and some of its Compounds; and, in particular, the "Swan" Spectrum. By W. Marshall Watts, D.Sc.*

[Plate II.]

A LTHOUGH more than a century has passed since the base of a candle-flame, now known as the "Swan" spectrum, no complete agreement as to its origin has yet been reached. Swan $\ddagger$, who observed it in 1857 , attributed the spectrum to a hydrocarbon. He obtained the spectrum only by combustion of hydrocarbons. Van der Willigen \$ found that the spark-discharge between carbon poles gave the same spectrum as burning olefiant gas, and ascribes the spectrum to carbon. Attfield\| obtained the spectrum not only by the combustion of hydrocarbons, but also, most brilliantly, from the flame of dry cyanogen in dry oxygen, and also by the electric discharge in dry cyanogen, carbonic oxide, and carbon disulphide vapour at atmospheric pressure. Since these substances have only carbon in common, " unless the experiments are vitiated by impurities, they prove undoubtedly that this spectrum is due to the element carbon"q. Dibbits** arrived at the same conclusion as Attfield. In answer to the objection raised that carbon could not exist as vapour in the flame of a candle or of a Bunsen burner, Dibbits argues that carbon is combined with hydrogen before the combustion, and after the combustion that carbon is combined with oxygen, and during the combustion it may have been in an uncombined condition : a flame of carbonic oxide does not show the same spectrum because the carbon is already combined with oxygen. In the case of cyanogen the carbon is at first combined with nitrogen, and after the combustion it is combined with oxygen, so that the same explanation applies $\dagger$.

* Communicated by the Author.

+ Wollaston, Phil. Trans. 1802, p. 365.

$\ddagger$ Swan, Phil. Trans. Edinb. xxi. p. 411 (1857).

$\$$ Vun der Willigen, Pogg. Ann. evii. p. 473 (1859).

\| Attfield, Phil. Trans. clii. p. 221 (1862); Phil. Mag. xlix. p. 106 (1875).

I Schuster, B. A. Report, 1880.

** Dibbits, Pogg. Ann. cxxii. p. 497 (1864).

t+ Note. In the case of cyanogen burning in oxygen the temperature probably reaches the volatilization-point of carbon, or that of the electric arc, viz. $3500^{\circ}$ to $3700^{\circ} \mathrm{C}$. "The temperature of individual molecules in the respective flames of cyanogen and acetylene may reach a temperature of from six to seven thousand degrees." (Liveing and Dewar, Pruc. Ruy. Soc. No. 223, 1882.) 


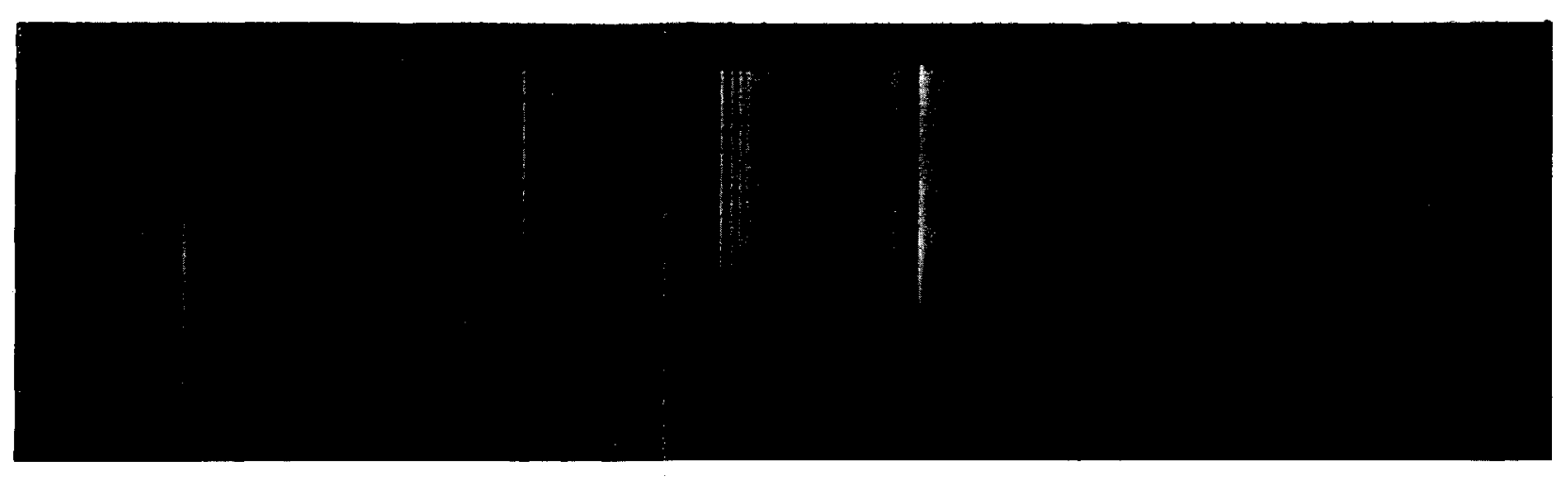

$\mathrm{Nil}$

Fir. 1.-Diffraction Spectrum of Bunsen flame.

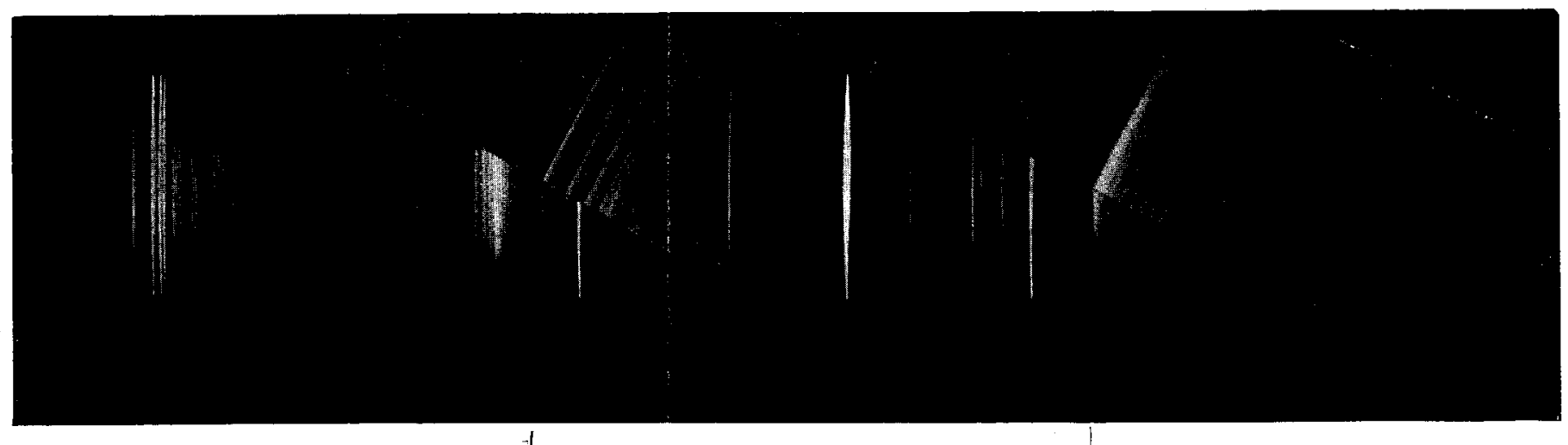

-1
4737

Fia, 3

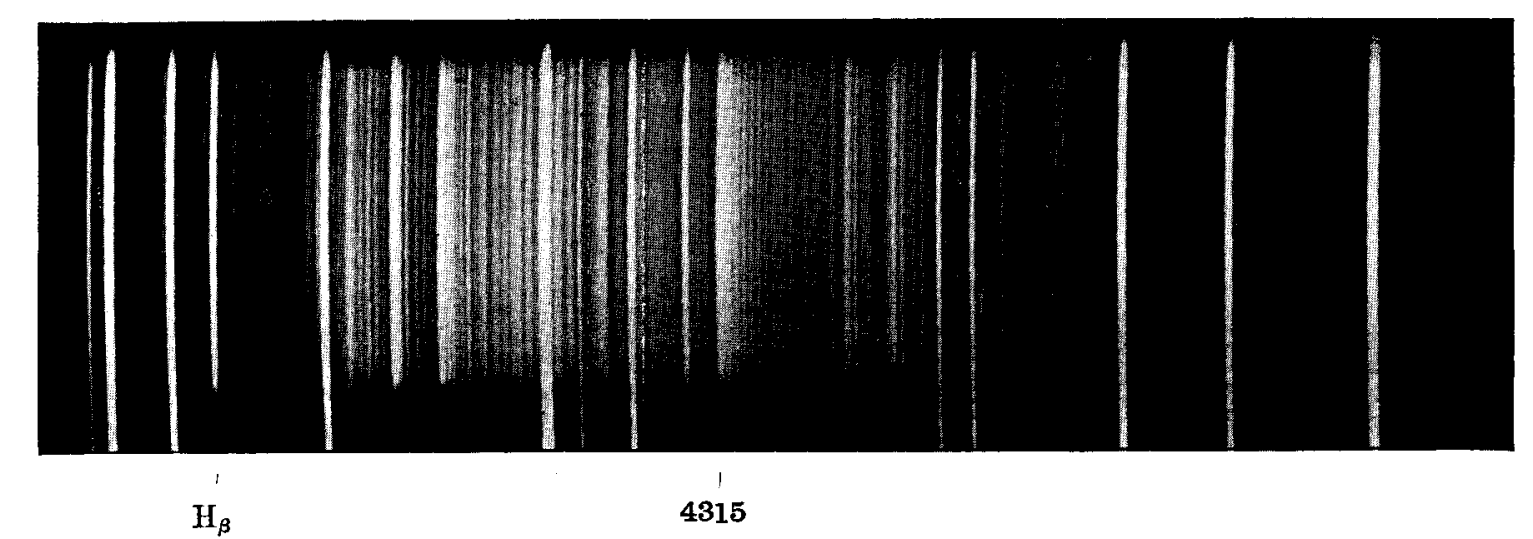

IG. 5.-Vacuum-tube, Helium and Hydrogen (prismatic), showing the hydrocarbon band.

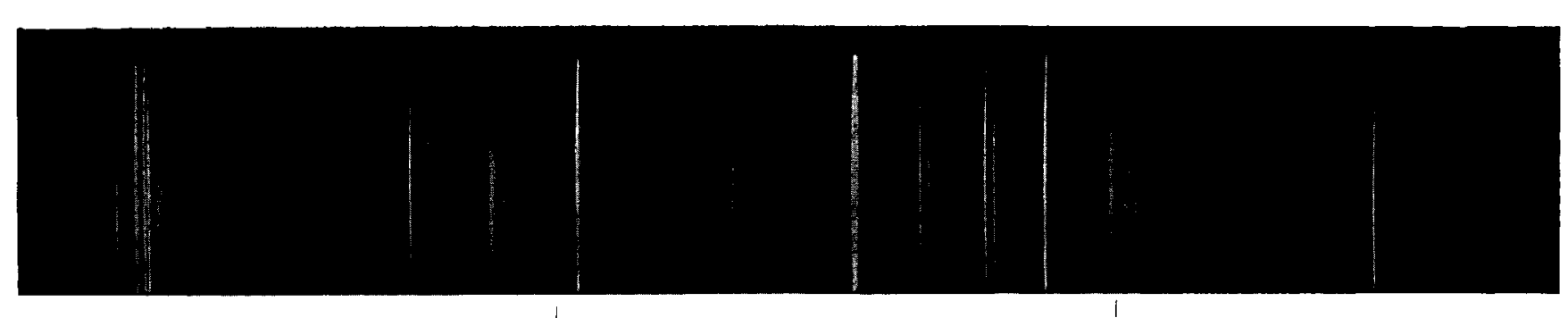

4315

Fic. 2.-Magnesium in coal-gas vacuum (Prismatic spectrum).

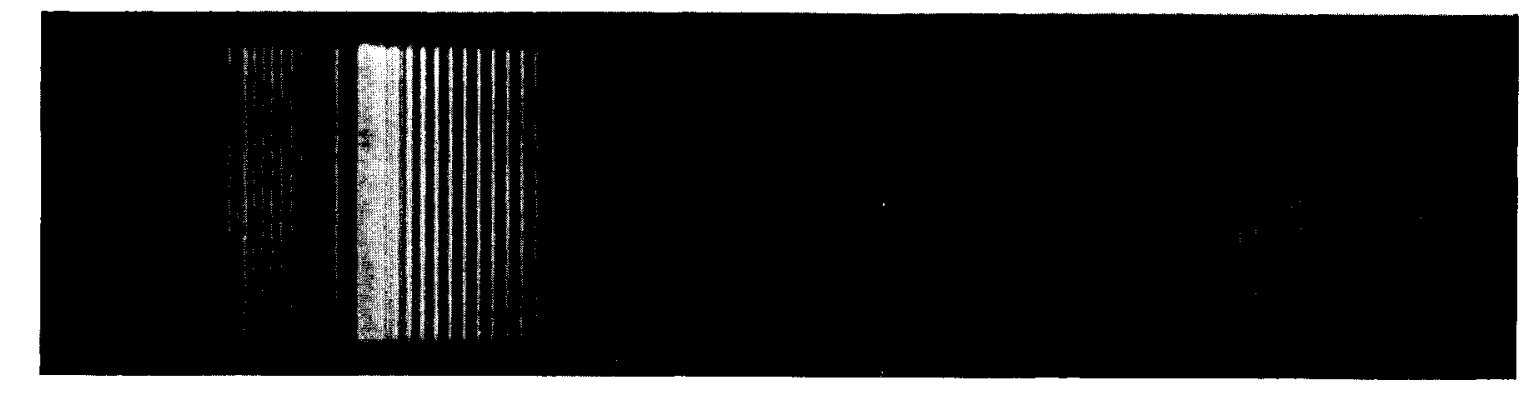

Fick. 4.-Hydrocarlon " $f$ " band. Photograjhed with grating spectrograph

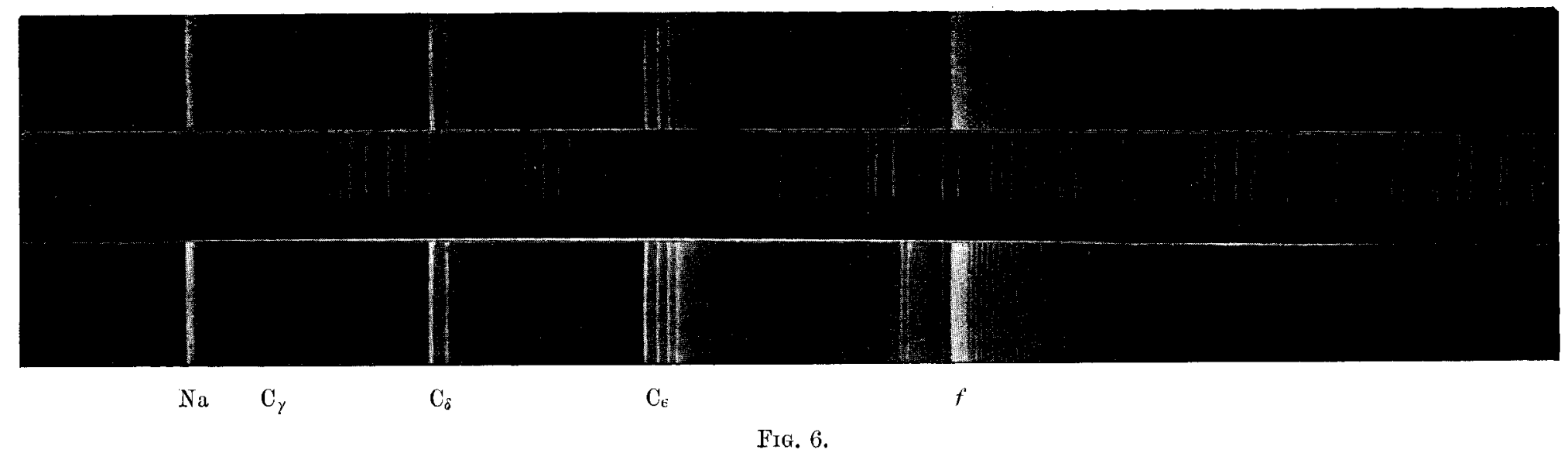


Morren * undertook experiments to prove that Attfield was wrong, but became convinced that he was right. $\mathrm{He}$ obtained the spectrum by burning eyanogen in oxygen, and also by taking the spark in cyanogen or acetylene at atmospheric pressure.

Plücker and Hittorf $\dagger$, Huggins $\ddagger$, Wül!ner $\$$, and Salet $\|$ all arrive at the same conclusion as Attfield. Schuster If in his Report of the Committee of the British Association "On the Present State of our Knowledge of Spectrum Analysis," wrote in 1880:- " On the whole it may be said that from the publication of Attfield's paper until the year 1875 every spectroscopist, whether he was a chemist or a physicist, who had set to work to decide the question, came to the conclusion that the candle spectrum was a true spectrum of carbon, and the question appeared to be settled. In the year 1875, after Angström's death, Thalén published a paper** in which he describes some experiments made jointly with Angströn. In consequence of these experiments the authors expressed the opinion that the candlespectrum was due to a hydrocarbon. The experiments which they gave in support of their view were made by taking the spark of carbon electrodes in various gases, and examining the spectra of the 'aureole' or 'glory' as it might be called. If the spark is taken in oxygen, the undoubted spectrum of carbonic oxide appears; in hydrogen the candle-spectrum is seen; and in nitrogen some blue and violut bands are added to the candle-spectrum which appear to be due to a compound of carbon and nitrogen. As it is known that acetylene is formed when the spark is taken in hydrogen, Angström and Thalén conclude that the spectrum seen in the 'glory' is duo to acetylene."

The theory of Angström and Thalen, that the "Swan" spectrum is due to a hydrocarbon, was adopted and maintained by Liveing and Dewart†. They examined the spectra seen in the electric arc between carbon poles in air, hydrogen, nitrogen, chlorine, carbonic acid, carbonic oxide, nitric oxide, and ammonia, and found that the green and blue bands of the "Swan" spectrum, well seen in hydrogen, less strong in

* Morren, Ann. Chim. Phys. iv. p. 305 (1865).

+ Plïcker ald Hittorf, Phil. Trans. clv. p. 1 (1865).

I Hurgins, Phil. Trans. clviii. p. 558 (1868).

\$ Wüllner, Pogg. Ann. cxliv. p. 481 (1872).

I Silet, Ann. C'him. Phys, xxviii. p. 60 (1873).

I! Schuster, B. A. Rep. 1880.

** Angström and Thalén, Nuva acta Reg. Soc. Sc. Upsal. ix. (3) (1875). t† Liveing and Dewar, Proc. Roy. Soc. xxx. pp. 152, 494 (1880). 
nitrogen or chlorine, were piesent in the arc, whatever the atmosphere. Nevertheless, putting aside the natural conclusion to be drawn from these experiments, they attribute the spectrum to hydrocarbon, the hydrogen being supposed to come from impurities. They also examined the spark in various gases with every precaution to exclude impuritiesin carbon tetrachloride and trichloride, in naphthaline aud between carbon poles in nitrogen. "In all the:e experiments the bands which Angström and Thalén ascribe to hydrocarbons were always more or less plainly seen" ". Again, Liveing and Dewar put aside the obvious conclusion, and attribute their results to the presence of hydrogen as an impurity.

Later $\dagger$, as the result of further experiments, Liveing and Dewar abandon the view tbat the "Swan" spectrum depends upon the presence of hydrogen. In these further experiments they found that "the spark betweon electrodes near together in wide tubes filled with saturated vapour of carbon disulphide or carbon tetrachloride dried with phosphoric anhydride and deprived as completely as possible of air by pumping or boiling out, shows the spectrum of the flame of hydrocarbons brightly. The flame of cyanogen from liquid cyanogen which had remained in contact with phosphoric anhydride or sulphuric acid gave the green line of the Swan spectrum together with the cyanogen bands; but when oxygen was used to raise the temperature of the flame all the hydrocarbon-flame sets appeared with marked brilliancy."

In another experiment the spark was observed in carbonic oxide at various pressures. The carbonic oxide was prepared by heating potassium oxalate and lime, and was dried over phosphoric anhydride. At atmospheric pressure the spark (without condenser) showed the spectrum of the bydrocarbon flame. On exhausting, the spectrum of carbonic oxide makes its appearance, superposed on the former; and as the exhaustion proceeds it increases in brilliance until it overpowers, and at last entirely supersedes the flame-spectrum. If the pressure of the gas is increased above the atmospheric, the hydrocarbon-flame spectrum grows brighter. [The linespectrum of carbon also appears at high pressures : the effect of increasing pressure being thus similar to that of introducing a condenser.] On letting down the pressure the same phenomena occur in the reverse order.

* Dewar, Proc. Ruy. Inst. June 101h, 1881. 418 .

+ Lireing and Dewar, Proc. Rny. Soc. No. 223 (1882), xxxir.pp. 128, 
Kayser, in the fifth volume of his great work Handbuch der Spectroscopie (1910), after describing the experiments of Ångström and Thalén, says: "I believe that the authority which, with perfect justice, was at that time attributed to the views of Angström upon spectroscopic matters is the reason that the Swan spectrum is by many still spoken of as the spectrum of hydrocarbons or of acetylene; although, in my opinion, this conclusion has been proved to be untenable."

Other experimenters who expressed the opinion that the "Swan " spectrum must be attributed to carbon were Secchi*, Lecoq de Boisbaudran $\dagger$, Ciamician $\ddagger$, Deslandres $\S$, and Eder $\|$. Eder T photographed the spectrum of burning hydrocarbons from the yellow into the ultra-violet as far as 2449: the five groups of bands in the red, yellow, green, blue, and violet (the "Swan" spectrum) he assigns to carbon, and the very strong bands in the ultra-violet he assigns to watervapour.

In a paper on "The Spectra of Carbon Compounds" in the Philosophical Magazine for 1901, Prof. Smithells** advances a new view of the origin of the "Swan" spectrum and of the spectrum of carbon monoxide or dioxide in a Geissler tube, attributing the first to carbon monoxide and the second to carbon dioxide. Prof. Smithells's defence of his position is based, for the most part, upon a study of the phenomena of flames. He seeks to set aside the natural conclusion to be drawn from the repeated observations of the "Swan" spectrum in carbon compounds not containing oxygen by the suggestion that it is impossible to free these substances from water, and other impurities containing oxygen, and points to the difficulty of removing films of air or moisture from glass, the occlusion of gases by electrodes, and the fact that glass itself contains oxygen as forming wellrecognized difficulties, quite apart from the purely chemical difficulties of obtaining pure materials.

I have now to describe experiments in which the "Swan" spectrum was observed in the absence of oxygen as far as it

* Secchi, C. R. lxxvii. p. 173 (1873).

+ Lecoq de Boisbaudran, Spectres lumineux, p. 43 (1874).

业 Ciamician, Szb. Wien, lxxii. (ii.) p. 425 (1880).

\$ Deslandres, C. R. cvi. p. 842 (1888); Ann. Chim. Phys. xv. p. 5.

II Eder, Beiträge zur Photochemie, 1890.

If Eder's photograph of the spectrum of the Bunsen flame obtrined by 36 hours' exposure on an Frytbrosin plate shows $\mathrm{C}_{\gamma}, \mathrm{C}_{\delta}, \mathrm{C}_{\boldsymbol{f}}$, and $f$, with "the three" lines, and the "fine-grained "structure from 4315, and tbe "conrse-grained" structure up to 3873 . (See figs. 1 \& 4.)

** Smithells, Phil. Mag. i. p. 476 (1901). 
is possible to secure that condition. The expense of this investigation was defrayed by a Government grant from the Royal Society; and the experiments were (partly) mude at the Davy-Faraday Research Laboratory. I am indebted for specially purified materials to Sir Edward Thorpe, for heptane from Pinus Sabiniana, and to Prof. Sydney Young for normal hexane, normal octane, carbon tetrachloride, and chlorobenzene.

In order to avoid oxygen contamination, as far as possible, a discharge-vessel made of fluor-spar was employed. This consisted of a rectangular block of transparent colourless fluor-spar, with a cylindrical cavity, the bottom of which was closed by a copper electrode ground into the spar. 'The upper electrode consisted of a platinum wire. The fluor-spar vessel was contained in a large glass test-tube, the mouth of which was closed by an indiarubber stopper through which the upper electrode passed, and which was also connected to an air-pump. A platinum wire sealed into the bottom of the glass tube made contact with the lower copper electrode.

The liquid under examination was distilled over phosphoric anhydride into the fluor-spar vessel, and the tube was kept exhausted. The upper electrode was heated red-bot within the liquid by causing the two electrodes to touch for a short time, and the spectrum was observed with a minute spark within the liquid which presently boiled. On account of the rapid separation of carbon, only a few seconds were available for observation, and consequently it was impossible to photograph the spectrum.

The results obtained were exactly the same as those reported in the Philosophical Magazine for $1906^{*}$. No difference was observed as the result of employing these liquids of extra purity and of the extra precautions taken to exclude traces of oxygen; nor does the intentional introduction of traces of oxygen affect the result.

Heptane gave a brilliant "Swan" spectrum in which the groups $\gamma(5635 \& e),. \delta(5165 \& c),. \epsilon(4737 \& c$.$) and f(4315 \& \mathrm{c}$. were identified.

Hexane and octane gave the same result, as did also carbon tetrachloride and chlorobenzene; but with these last the observations are more difficult and the blackening more rapid.

The first observations of the spark within liquids seem to be those of Danielt. He experimented with ether, alcohol,

* Watts and Wilkinson, Phil. Mag. xii. p. 581 (1906).

+ Daniel, C. R. lvii. p. 98 (1863). 
carbon disulphide, turpentine, benzene, aniline, naphtla, chloroform, ethylene dichloride, ethyl chloride, ethyl bromide, and ethyl iorlide; and in all cases observed the "Swan" spectrum.

Konen * also observed the spark in liquids, and obtained the "Swan" spectrum with all carbon-containing liquids, chloroform, benzene, carbon disulphide, carbon tetrachloride, ariline, and petroleum.

It would seem that the spark in a liquid containing carbon and no oxygen offers the best chance of escaping oxygencontamination. We have then really a discharge in a small gas-filled cavity of which the walls consist of the liquid itself'.

Wilsing + , who also observed the discharge in liquids, remarks, "One may hope in this way to obtain the percentage of impurities greatly less than in Geissler tubes, which coutain only small quantities of the substance to be examined with relatively large quantities of gases derived from the glass, from the pump, or from the electrodes."

Observations with the arc burning under liquids give the same results, but the difficulties of excluding impurities are greater than with the spark.

Konen $\ddagger$ observed the "Swan" spectrum from the arc burning under alcohol, glycerine, carbon tetrachloride, carbon disulphide, aniline, and petroleum, and also under water if carbon rods were used.

La Rosa § has observed the "Swan" spectrum in the glow surrounding an intensely-heated carbon rod. The image of the glowing rod ( 2 or $3 \mathrm{~mm}$. in diameter) thrown on the slit of the spectroscope gave an intense continuous spectrum, and outside that a weaker and broader spectrum on which are seen the "Swan" bands : $\gamma 5635$ with four or five edges; $\delta$ at 5165 with three or four edges : $\epsilon$ at 4737 with four edges and three lines at 4383 . On raising the incandescence to the maximum 5165 was reversed. No cyanogen lines are seen because the nitrogen of the air is prevented from reaching the rod by the surrounding atmosphere of carbon vapour. For the same reason oxygen cannot reach the rod: therefore the spectrum is not due to carbon plus oxygen, but to carbon vapour only.

The experiment was repeated with the same result in a space as free from oxygen as possible.

* Konen, Ann. d. Zhys. ix. p. 742 (1902).

+ Wilsing, Szb. Berlin, 1899, pp. 426, 750 .

I Konen, Ann. d. Phys. ix. p. 742 (1902).

\$ La Tiosa, Auu. d. Plygs. xxxiv. p. 220 (1911). 
In connexion with these experiments of La Rosa may be mentioned the observation which has frequently been made*, that an ordinary carbon-filament incandescent lamp in which the current is increased till the filament gives way shows a flash of the "Swan" spectrum, due, no doubt, to the volatilization of carbon vapour at the moment of disruption.

The following summary of wave-length measurements of the chief lines of the band spectra of carbon and of some of its compounds will be useful for reference.

\begin{tabular}{|c|c|c|c|c|c|}
\hline & $\begin{array}{l}\text { Angströın } \\
\text { \& 'líalén. }\end{array}$ & Hasselberg. & $\begin{array}{c}\text { Kayser \& } \\
\text { Runge. }\end{array}$ & $\begin{array}{c}\text { Eder \& } \\
\text { Valenta. }\end{array}$ & \multirow{2}{*}{$\begin{array}{l}\text { Fuwler. } \dagger \\
6191 \cdot 1 \\
\mathbf{6} 121 \cdot 8 \\
6059 \cdot 9 \\
6005 \cdot 1 \\
54582\end{array}$} \\
\hline $\begin{array}{l}\text { Red. } \\
\text { Group } \mathrm{I} . \\
\mathrm{C}_{\dot{\alpha}} .\end{array}$ & $\begin{array}{l}6187 \cdot 3+09 ? \\
6119+0 \cdot 9 ? \\
6056 \cdot 3+1 \cdot 0 ? \\
61000 \cdot 8+10 ? \\
5953 \cdot 5+1 \cdot 0 ?\end{array}$ & $\begin{array}{l}6186.4+09 ? \\
6121 \cdot 0+09 ? \\
6050 \cdot 8+1 \cdot 0 ? \\
5993 \cdot 0+0.9 ? \\
5951 \cdot 0+1.0 ?\end{array}$ & $\begin{array}{l}\ldots \ldots \ldots . . \\
\ldots \ldots \ldots . . \\
\ldots \ldots \ldots \ldots . \\
\ldots \ldots \ldots . . \\
\ldots \ldots \ldots .\end{array}$ & $\begin{array}{l}6188 \\
6120 \\
6052 \\
5999 \\
5455\end{array}$ & \\
\hline $\begin{array}{c}\text { Yellow-green. } \\
\text { Group II. } \\
C_{\gamma \cdot} \\
\text { (Eder's } \beta .)\end{array}$ & $\begin{array}{l}56330+1 \cdot 0 ? \\
5583 \cdot 0+1 \cdot 1 ? \\
55380+1 \cdot 0 ? \\
55000+1 \cdot 1 ? \\
54660+0 \cdot 9 ?\end{array}$ & $\begin{array}{l}5636 \cdot 4+10 ? \\
5585 \cdot 1+1 \cdot 1 ? \\
5537 \cdot 5+1 \cdot 0 ? \\
5500 \cdot 6+1 \cdot 1 \\
5 \pm 71 \cdot 6+0 \cdot 9 ?\end{array}$ & $\begin{array}{c}5635.43 \\
5585.50 \\
5540.86 \\
\ldots \ldots \ldots . \\
\ldots \ldots \ldots .\end{array}$ & $\begin{array}{c}{[5635.43]} \\
{[5585500} \\
{[0540 \cdot 86]} \\
5501 \\
5471\end{array}$ & $\begin{array}{c}\text { Komp. } \\
(\text { I. A.) } \\
5635.504 \\
5585.493 \\
5540 \cdot 890 \\
5501.914 \\
5572.670\end{array}$ \\
\hline $\begin{array}{c}\text { Emerald-green. } \\
\text { Group III. } \\
\text { Od. }_{\delta} \\
(\text { Eder's } \gamma .)\end{array}$ & $\begin{array}{l}5164 \cdot 0+0 \cdot 9 \\
5128 \cdot 0+0 \cdot 8 \\
5097 \cdot 7+0 \cdot 8 \\
5082 \cdot 4+0 \cdot 8 \\
50792+0 \cdot 8\end{array}$ & \begin{tabular}{|}
$5164 \cdot 4+0 \cdot 9 ?$ \\
$5128 \cdot 2+0 \cdot 8 ?$ \\
$5096 \cdot 9+0 \cdot 8 ?$ \\
$\ldots \ldots \ldots \ldots$
\end{tabular} & $\begin{array}{r}516.530 \\
5199 \cdot 36 \\
\ldots \ldots \ldots \\
\ldots \ldots \ldots\end{array}$ & $\begin{array}{c}{[5165 \cdot 30]} \\
{[124 \cdot 36]} \\
5096 \\
5084\end{array}$ & $\begin{array}{c}\text { Leinen. } \\
5165.473 \\
5129.579\end{array}$ \\
\hline $\begin{array}{c}\text { Blue. } \\
\text { Grump IV. } \\
C_{0 .} \\
(\operatorname{Eder} \& \delta .)\end{array}$ & $\begin{array}{l}4736 \cdot 0+0 \cdot 9 ? \\
4714 \cdot 0+0 \cdot 9 ? \\
4697 \cdot 0+0 \cdot 9 ? \\
468 \cdot 0+09\end{array}$ & $\mid \begin{array}{l}4734 \cdot 8+0.9 ? \\
4712 \cdot 8+0.9 ? \\
4695 \cdot 3+0.9 ? \\
4683.5+0.9 ? \\
4676.7+09 ?\end{array}$ & 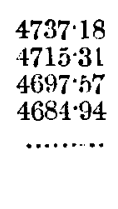 & $\begin{array}{l}4737 \cdot 25 \\
471 \cdot 37 \\
4697 \cdot 66 \\
468+58 \\
4680 \cdot 25\end{array}$ & $\begin{array}{l}4737 \cdot 147 \\
4715 \cdot 453 \\
4697 \cdot 601 \\
4683 \cdot 491 \\
4672 \cdot 979 \\
4666 \cdot 100 \\
4662 \cdot 848\end{array}$ \\
\hline
\end{tabular}

These four groups are followed in the spectrum as given by the Bunsen flame by a group Cf of conplicaled structure, consisting of a band shaded by fine lines from about 4371 to 4335 , separated ky a fine detached line 4324 from a strong edge at 4315 , which forms the commencement of a shaded field extending to 3873. The luminosity of this field falls off from 4315 towards the violet, and then increases again to

* Liveing and Dewar, Proc. Roy. Soc. xxxiii. p. 403 (1882).

+ 'Index of Spectra,' App. V. p. 67. 
end at 3873 with a fairly strong edge. The fine shading lines are closer together at the less refrangible edge 4315 than those which form the more refrangible edge at $3871^{*}$.

There are three marked lines at $4381 \cdot 93,4371 \cdot 31$, and 4365.01 superposed upon the first portion of this group $f$.

These three lines seem to have been first noticed by Liveing and Dewar, who attributed them to cyanogen, an opinion which they retracted later $\dagger$. In 1889 Kayser and Runge $\ddagger$ pointed out that they are probably part of the "Swan" spectrum ; and adduced evidence from the relationship of their wave-lengths to those of the other groups of the "Swan" spectrum.

Deslandres $\$ 1891$ re-discovers these lines and calculates what their wave-lengths should be. He makes the erroneous statement that they are not produced by the combustion of hydrocarbons $\|$, but only in the arc and in the flame of cyanogeu. Deslandres" paper is entitled "A new method for the discovery of faint bands, \&c." He says: "I have studied the band-spectrum attributed to hydrocarbons or to carbon itself by a new method by which I have been able to complete it, and to add to it with certainty three new bands at $438 \cdot 19,437 \cdot 13$, and 436.5 . . The application of the general law of arrangement of bands which I gave in 1887 permits me to conclude that these three bands belong certainly to the hydrocarbon bands."

The calculations of Kayser and Runge (of 1889) are criticised by Deslandres in the Journal de Physique for June 1891, who there repeats the statements quoted above from the Comptes Rerdus.

There is no doubt that a numerical relationship exists between the wave-lengths of the lines of the "Swan" spectrum, that is between $\mathrm{C}_{\alpha} \mathrm{C}_{\gamma} \mathrm{C}_{\gamma} \mathrm{C}_{e}$ and "the three"; but the group $f$ and more refrangible group will not fall into line with the rest. Deslandres' formulæ are approximately correct, as may be seen from the following recalculation with the more exact data now available; but we are still in want of sufficiently good measurements of the red lines and of some others.

* The fine-grained shading at the less refrangible edge and the coarsegrained shading at the more refrangible edge are seen in the photngraphs of the Bunsen spectrum given by Eder, Szb. Wien, xciv. p. $\Delta 03$ (1886), and by Vogel, Szb. Berlin, xxi. p. 523 (1888), as well as in the reproductions which accompany this paper.

+ Liveing and Dewar, P. R. S. xxxiv. p. 418 (1882).

$\mp$ Kayser and Runge, Abhandl. Berlin Akad. 1889.

Deslandres, C.R. exii. p. 661 (1891).

II See the photograph of the spectrum of the Bunsen flame given by Eder, Szb. Wien, xciv. p. 403. 
The formulæ employed are :-

$$
\begin{aligned}
& \text { For } \alpha_{1} \gamma_{1} \delta_{1} \quad \text { O.F. }=-24654 \cdot 04+15 \cdot 094 m^{2}[m=53.54 .55] \text {, } \\
& \alpha_{2} \gamma_{2} \delta_{2} \varepsilon_{1} \quad \text { O.F. }=-23784 \cdot 84+14 \cdot 841 \mathrm{~m}^{2}[m=53.54 .55 .56], \\
& \alpha_{3} \gamma_{3} \delta_{3} \varepsilon_{2} \text { (1) O.F. }=-23015 \cdot 6 \tau+14 \cdot 6184 m^{2}[m 53.54 .55 .56 .57] \text {, } \\
& \alpha_{4} \gamma_{4} ? \varepsilon_{3}(2) 0 . \mathrm{F}=-22138 \cdot 65+14.355 m^{2}[m 53.54(55) 56.57] \text {, } \\
& \alpha_{5} \gamma_{3} ? e_{4}(3) \text { O.F. }=-21396 \cdot 13+14 \cdot 1293 m^{2}[m 53.54(55) 56.57] \text {. }
\end{aligned}
$$

There is little doubt that the older measurements of the red lines are in error, and $I$ have not found it possible to combine Deslandres' five formulæ into one. The following is a more satisfactory formula, for which I am indebted to my friend, Rev. P. H. Jones, M.A., R.N.

\begin{tabular}{|c|c|c|c|}
\hline Observed. & \multicolumn{2}{|c|}{ Calculated Values (in Air). } & Observed. \\
\hline $\begin{array}{c}\text { Angström \& } \\
\text { Thalén. } \\
6188 \cdot 2 \\
6119 \cdot 9 \\
6057 \cdot 3 \\
6001 \cdot 8 \\
\overline{5904} \cdot 5\end{array}$ & $\begin{array}{r}\text { Deslandres. } \\
\text { (53) } 6188 \cdot 06 \\
6117 \cdot 98 \\
605601 \\
5996 \cdot 19 \\
5949 \cdot 03\end{array}$ & $\begin{array}{c}\text { Jones. } \\
(45,67) 6191.02 \\
6121.80 \\
6059 \cdot 98 \\
6005 \cdot 18 \\
5957.02\end{array}$ & $\begin{array}{l}\text { Fowler. } \\
6191 \cdot 1 \\
6121 \cdot 8 \\
6059 \cdot 9 \\
6005 \cdot 1 \\
5958 \cdot 2\end{array}$ \\
\hline \begin{tabular}{|c|} 
Kayser \& Runge. \\
6635.43 \\
5585.50 \\
5540.86
\end{tabular} & $\begin{array}{r}\text { (5+) } \mathbf{5 6 3 5 \cdot 4 0} \\
\mathbf{5 5 8 5} \cdot 48 \\
\mathbf{5 5 4 0 \cdot 9 5} \\
\mathbf{5 4 9 9 \cdot 1 7} \\
\mathbf{5 4 6 6 \cdot 5 5}\end{array}$ & $\begin{array}{r}(45,68) 5635 \cdot 715 \\
5585 \cdot 500 \\
5541 \cdot 181 \\
5502 \cdot 364 \\
5468 \cdot 906\end{array}$ & 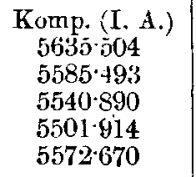 \\
\hline $\begin{array}{l}5165 \cdot 30 \\
5129 \cdot 36\end{array}$ & $\begin{array}{r}\text { (55) } 5165 \cdot 27 \\
5130 \cdot 42 \\
5099 \cdot 01 \\
5070 \cdot 85\end{array}$ & $\begin{array}{r}(45,60) 5165 \cdot 592 \\
5129 \cdot 578 \\
5098 \cdot 134 \\
5071 \cdot 254\end{array}$ & $\begin{array}{l}\text { Lein } \\
5165 \\
5129\end{array}$ \\
\hline $\begin{array}{l}4737 \cdot 18 \\
4715 \cdot 31 \\
4697 \cdot 57 \\
4684 \cdot 94\end{array}$ & $\begin{array}{r}\text { (56) } 4737 \cdot 28 \\
4715 \cdot 86 \\
4698 \cdot 09 \\
4684 \cdot 94\end{array}$ & $\begin{array}{r}(44,69) 4736 \cdot 131 \\
4715 \cdot 523 \\
4697.632 \\
4683.415 \\
4671791\end{array}$ & $\begin{array}{c}\text { Hindrichs. } \\
\mathbf{4 7 3 7} \cdot 147 \\
4715 \cdot 453 \\
4697 \cdot 601 \\
4683 \cdot 491 \\
4672 \cdot 979\end{array}$ \\
\hline $\begin{array}{l}4381 \cdot 93 \\
4: 91 \cdot 31 \\
4365 \cdot 01\end{array}$ & $\begin{array}{r}\text { (57) } 4380 \cdot 66 \\
4370 \cdot 90 \\
4364 \cdot 27\end{array}$ & $\begin{array}{r}(43,69) \\
4381 \cdot 65 \\
4370 \cdot 85 \\
4362 \cdot 95\end{array}$ & 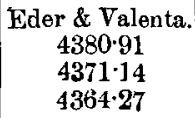 \\
\hline
\end{tabular}

O.F. $($ in vacuo $)=2407 \cdot 015-19 \cdot 6(p+\cdot 00309)^{2}+11 \cdot 6422(m+\cdot 834291)^{2}$ where $p=45,44,43$, and $m=63,64,65,66,67,68,69$.

The following table shows the agreement between the calculated values and those observed. 
It may be concluded, I think, that the three lines form a part of the "Swan" speetrum; but the shaded band $f$ upon which they are superposed probably does not belong to the same spectrum, though always seen in the combustion of hydrocartons, in the discharge in liquids containing car on and hvdrogen, or carbon, hydrogen, and oxygen, and occasionally in vacuum-tubes. There is, I believe, no evidence that it is due to carbon alone; but there is evidence that hydrogen is necessary for its production, and therefore it may, provisionally at least, be termed the hydrocarbon band.

The group $f$ is seen in Vogel's photograph of the spectrum of the cyanogen flame (Berliner Berichte, xxi. 1888).

In my early observations of the direct discharge in carbon monoxide at atmospheric pressure which shows the "Swan" spectrum, I sometimes observed $f$ and sometimes the cyanogen bands $\zeta$ and $\theta$ instead of $f$, a slight alteration of the electrical conditions producing the change. Ii is now clear that the gas used in these experiments contained both water-vapour and nitrogen as impurities. The "Swan" spectrum in carbonic oxide usually shows $f$, unless the gas is very thoroughly dried; but that it can be so completely dried that $f$ disappears is shown by the photograph of the spark in the gas at atmospheric pressure (Pl. II. fig. 6), for which I am indebted to my friend Mr. E. E. Brooks. The two outside strips are the spectrum of the Bunsen flame, and the central strip that of dry carbonic oxide together with the iron arc. It can be seen that $f$ has disappeared, but that "the three" lines 4381,4371 , and 4364 remain.

Fig. 2 shows Mr. Brooks's spectrum of magnesium in a coal-gas racuum*, ald in fig. 3 portions of the Bunsen-flame spectrum are fitted on to this to show the presence of the groups $f$ and $C_{i}$ in the electric spectrum.

Figs. 4 and 5 are photographs for which I am indebted to my friend Mr. C. W. Raffety, the first of the $f$ group from a Mecker burner, and the second of a hydrogen racuum-tube in which the group $f$ is seen amongst the lines of the secondary hydrogen spectrum.

We have thus evidence of the production of the $f$ group in carbonic oxide with a trace of hydrogen, and in hydrogen with a trace of carbonic oxide.

The "Swan" spectrum predominates at the negative pole both in vacuum-tubes and in the arc, whereas the spectrum of carbonic oxide is seen most brightly at the positive pole.

In 1902 I observed in a vacuum-tube containing coal-gas

* See P. R S. 1xxx. p. 218 (1968), and Kayser, Hdb. Spect. v. p. 232. 
at a pressure of $100 \mathrm{~mm}$. the "Swan" spectrum and the carbonic-oxide spectrum simultaneously. As the pressure was decreased the "Swan" disappeared and the carbonicoxide spectrum remained; but in the intermediate condition the two ends of the capillary were of different colours, - the negative end decidedly blue showed the "Swan" brightest; whereas at the positive end the carbonic-oxide spectrum was the brightest.

Liveing and Dewar*, who observed the "Swan" spectrum in an incandescent carbon lamp at the moment at which the filament gave way, also observed a sort of flame giving the carbonic-oxide spectrum at the point where the filament joined the positive wire.

Baldwint (in "a photographic study of arc-spectra") says, "The central arc is violet, outside this a blue sheath strongest at the negative carbon and surrounded by an outer yellow sheath shading into orange at the outside. The flame which starts at the negative carbon extends some distance up the positive carbon."

Hagenbach $\neq$, describing the arc between copper poles in an atmosphere of carbon dioxide, says:- "The positive electrode was always hotter than the negative electrode; with decreasing pressure this difference became more marked, and at 10 to $20 \mathrm{~mm}$. the negative elentrode never became red-hot. The bands of carbon oxide $6622 \cdot 0,6078 \cdot 0,5607 \cdot 5,5197 \cdot 0$, $4836 \cdot 5,4509 \cdot 0,4394 \cdot 0,4209^{\circ} 0$, and $4130 \cdot 0$ were seen especially at the positive pole. The 'Swan' spectrum 6188, $5634,5164,4736,4375$ to 4325,4315 , and 3890 to 3873 became more intense and sharper with decreasing pressure, but was absent from the positive pole."

A study of the results obtained by Sir J. J. Thomson $\S$ leads to the conclusion that the "Swan" spectrum is due to the negatively-charged carbon atom, and not to either carbon monoxide or carbon dioxide.

The Swan spectrum is given by carbonic oxide at atmospheric pressure, but not by carbon dioxide. In carcon monoxide as the pressure is reduced $\|$ the Swan dies away, and at low pressures is completely replaced by the second spectrum. This indicates that carbon monoxide contains something not present in carbon dioxide, but that this something gets smaller in amount as the pressure is reduced.

* Liveing and Dewar, Proc. Roy. Soc. xxxiii. p. 403 (1882).

+ Baldwin, Phys. Rev, iii. p. 370 (1895).

t Hagenbach, Phys. Zs. x. p. 649 (1910).

\$ Thomson, 'Nature,' Ixxxvi. p. 466 (1911).

"1 Deslindres, C. R. cvi. p. 84: (1889); Ann. Chim. Phys. xr. p. 72. 
Now Thomson finds that both carbon monoxide and carbon dioxide contain $\mathrm{C}++, \mathrm{O}++, \mathrm{C}+, \mathrm{O}+, \mathrm{CO}_{2}+$, and $\mathrm{CO}+$, whereas carbon monuxide alone contains $\mathrm{C}-$.

Further, Thomson show's that such negatively charged atoms ought to be, and are, less numerous when the discharge has difficulty in passing, $i$. $e$. at low pressures.

The spectrum given by carbon oxide at low pressures is also generally seen in vacuum-tubes enclosing hydrocarbons ; but there is evidence that oxygen must be present. Whether this spectrum is to be attributed to $\mathrm{CO}+$ or $\mathrm{CO}_{2}+$ there is, at present, nothing to show, so far as I am aware.

XV. On the Shape of the Capillary Surface inside a Tube of Small Radius, with other Allied Problems. By AlLAN Ferguson, B.Sc. (Lond.), Assistant-Lecturer in Physics in the University College of North Wales, Bangor*.

$\S 1$. $\mathrm{THE}$ present paper is devoted to the formation of a closer approximation than usual to the outline of the surface of a liquid contained in a vertical tule of small bore, and to the application of the formulæ developed to certain cases of practical interest.

With axes as shown in fig. 1 , and symbols having the significance there indicated, the differential equa tion to the surface of the liquid will be

$$
g \rho(y+h)=\mathrm{T}\left(\frac{1}{\mathrm{R}_{1}}+\frac{1}{\mathrm{~K}_{2}}\right),
$$

where $R_{1}$ and $R_{2}$ are the principal radii of curvature at the point $P$. Substituting their values and putting $a^{2} \equiv \mathrm{T} / g \rho$, this becomes

$$
a^{2} x \frac{d p}{d x}+a^{2} p\left(1+p^{2}\right)=x(y+h)\left(1+p^{2}\right)^{\frac{3}{2}}
$$

Fig. 1.

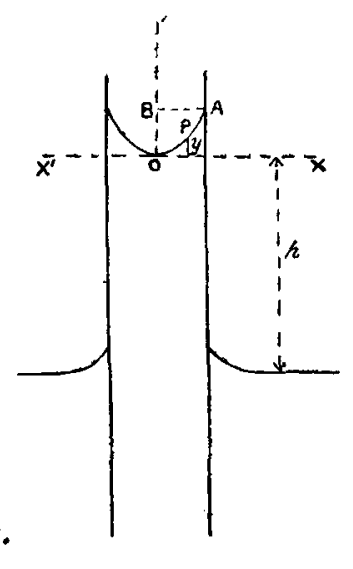

Putting $p=\tan \phi$, and $z=\sin \phi$, we readily find

$$
\frac{d z}{d x}+\frac{z}{x}=\frac{y+h}{a^{2}} \text {. . . . . . . }
$$

* Communicated by Prof. E. Taylor Jones. 